investigación es haber encontrado estos textos litúrgicos en los manuscritos que se utilizaban para los ritos -mozárabe y romano- de la época en que se estaba construyendo el claustro de Silos. Más aún, el mismo monasterio poseía libros litúrgicos que contenían estos formularios.

Como idea central del trabajo, pienso que, aunque lo expuesto no nos llevan a demostrar que el autor o diseñador de la iconografía de la Ascensión de Silos tuvo como fuente de contenido las homilías de los Padres y las oraciones de la liturgia designadas para la fiesta de la Ascensión del Señor, sí es una posibilidad muy probable. El responsable de haber representado al Cristo de la Ascensión sólo por su cabeza pudo muy bien haberse inspirado en los textos litúrgicos que recitaba y escuchaba en las celebraciones cada año. Aunque, como hemos visto, los textos no son originales de Silos y en cualquier lugar donde se recitasen hubiera podido surgir esta iconografía, pudo ser que el artista de Silos, sin dejar de estar influenciado por ciertas fuentes gráficas de las representaciones de su época y anteriores, fuera más sensible y perspicaz, más original y avispado para idear una nueva iconografía a partir de un contenido teológico contenido en la liturgia. No se conformó con representar el hecho, de forma más o menos real e histórica basado en los relatos evangélicos y del libro de los Hechos de los Apóstoles, sino que, imbuido de la teología concreta que surge de los textos patrísticos y litúrgicos, idea una nueva y única forma de representar la Ascensión de Jesucristo a los cielos.

Creo que no resulta descabellado presentar esta hipótesis. La liturgia y sus textos son una fuente riquísima de inspiración; los eclesiásticos y especialmente los monjes estaban imbuidos de su vasto contenido; los manuscritos litúrgicos eran frecuentemente fuente gráfica de inspiración..., ¿cómo no pudieron ser estas oraciones, trascritas en los propios manuscritos de Silos, fuente de inspiración para el relieve de la Ascensión, máxime cuando uno de estos manuscritos, -el códice N.a.l. 2176 (fol. 265) de la BNP-, es con uno de sus dibujos, fuente de inspiración gráfica del relieve de la Depositio y la visitatio sepulcri de nuestro claustro, obra del mismo taller o autor ${ }^{61}$. Recordemos cómo autores, como M. Schapiro, Ben-Pechat y Ch. Pellistrandi, citados en este trabajo, vieron también en los textos patrísticos y litúrgicos la fuente de nueva iconografías. De esta manera, creemos haber hallado la solución al problema que surge de la original manera de representar al Cristo de la Ascensión en el primer relieve del claustro románico de Santo Domingo de Silos.

Otras preguntas que nos surgen a raíz de los investigado no las podemos responder por ahora. Algunas de ellas: ¿por qué esta iconografía no inspiró a otros artistas e influyo en otras obras posteriores?, ¿nos aporta algo lo descubierto para situar mejor la factura del relieve en el tiempo y, con ello, despejar sombras sobre el promotor del claustro?

Antonio Manuel Pérez, O.S.B.

\title{
UN NUEVO LIENZO DE VAN DYCK RESTITUIDO: LA VIRGEN CON NIÑO $Y$ ÁNGELES JUNTO A UN ROSAL DE LA CASA DUCAL DE OSUNA
}

La Virgen con Niño y ángeles junto a un rosal que restituimos a Van Dyck (fig. 1), es lienzo $(113 \times 113 \mathrm{~cm}$.) desconocido en los estudios y monografías más recientes del pintor. La referencia más próxima de la existencia de un original, es una copia antigua que publica el profesor Larsen (fig. 2) ${ }^{1}$. Con anterioridad, había catalogado el lienzo de la colección de los Osuna entre los

61 Ver nota 44.

${ }^{1}$ Lienzo, 110 x 92,5 cm. Suiza, Le Château, Monaz, Colección de la Señora André Muralt. Según el propietario, procede de la colección de Carlos X. [E. Larsen, The Paintings of Anthony van Dyck, II, 1988, p. 455, n A143a]. 


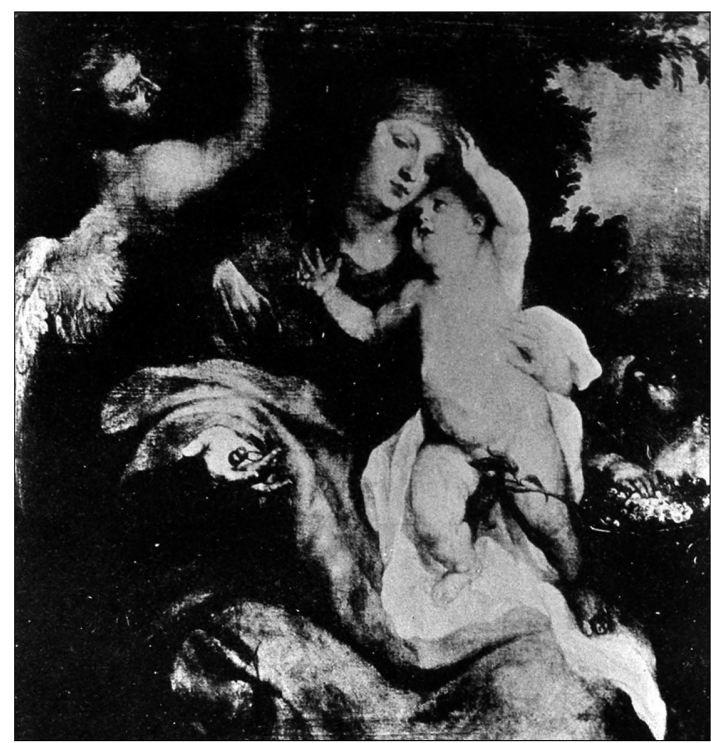

Fig. 1.Van Dyck, La Virgen con Niño y Ángeles junto a un rosa, Casa Ducal de Osuna.

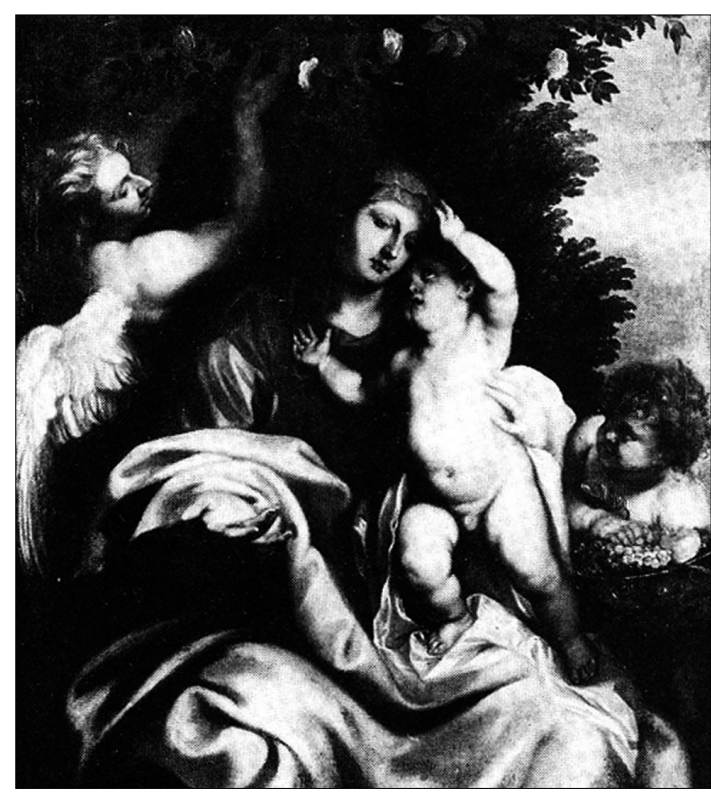

Fig. 2. Van Dyck, copia, La Virgen con el Niño, colección Mrs. André de Muralt, le Château, Monnaz, Vaud, Suiza.

originales del maestro flamenco en tesis doctoral inédita de $1976^{2}$. La reproducción fotográfica del siglo XIX de que dispongo, dificulta en alguna medida la visión de su calidad, que hoy reconocemos como su superioridad con respecto a la copia, que está lejos de la perfecta armonía de diseño y sutiles tonalidades del original de la colección Osuna.

El prestigio de esta colección y las referencias de los antiguos catálogos son razones a considerar para un juicio positivo. La diferencia de original y copia -al margen del análisis estético- está en pormenores del dibujo como las cerezas que lleva la Virgen en la palma de la mano derecha, que omite la copia, y la rama con hojas que cruza las piernas desnudas del Niño en la pintura de Madrid (con pudorosa intención de disimular su total desnudez). Es un hecho visible la interrupción brusca en la prolongación del árbol y las frutas que porta el ángel mancebo a la izquierda, lo que indica un corte en el lienzo que estudiamos de actual formato cuadrado. Un formato infrecuente en la obra de Van Dyck, que da motivo para pensar en una mutilación en lo alto del lienzo, hecho que ratifica la copia publicada por el profesor Larsen.

La distribución armónica de la Virgen y los ángeles en el frondoso paisaje es un logro de gracia y armonía rítmica. Ninguna pintura del tema alcanza tal grado de seducción. Está logrado el descanso de los cuerpos, como la fluida unidad psicológica de los personajes en el encuentro místico. Todos están ligados en el amoroso diálogo de María y Jesús Niño.

En la mayoría de las representaciones de Madre e Hijo, Éste desplaza la atención al distanciarse a un lado y a otro la Virgen en el escenario. Aquí la Virgen y el Niño dibujan con sus cuerpos unidos un triángulo ascendente en diagonal, bajo colinas con arboleda en un atardecer. El lírico diseño está en consonancia con la belleza de los modelos a que Van Dyck no renuncia. El sentimiento religioso que anida en el ambiente es auténtico y acredita la devoción católica del pintor. Al regresar de Italia, entró en la cofradía de Solteros (Solidaliteit), que tutela la Compañía de

2 M. DíAZ PAdRón, La pintura flamenca del siglo XVII en España, Ms., Madrid, 1976, II, fol. 446. 


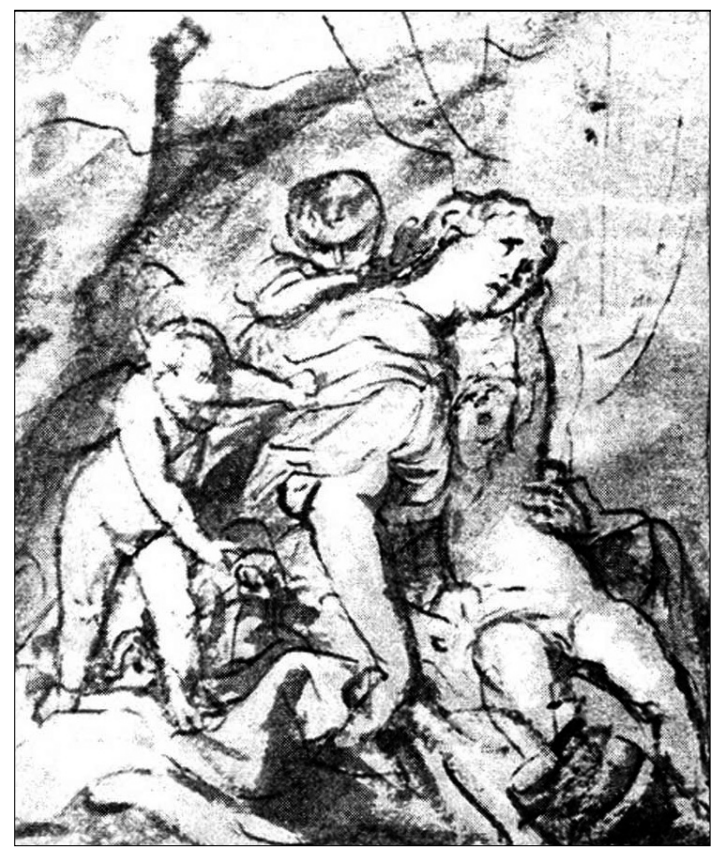

Fig. 3. Van Dyck, La Caridad, dibujo, Gabinete de Dibujos del Museo del Louvre, París.

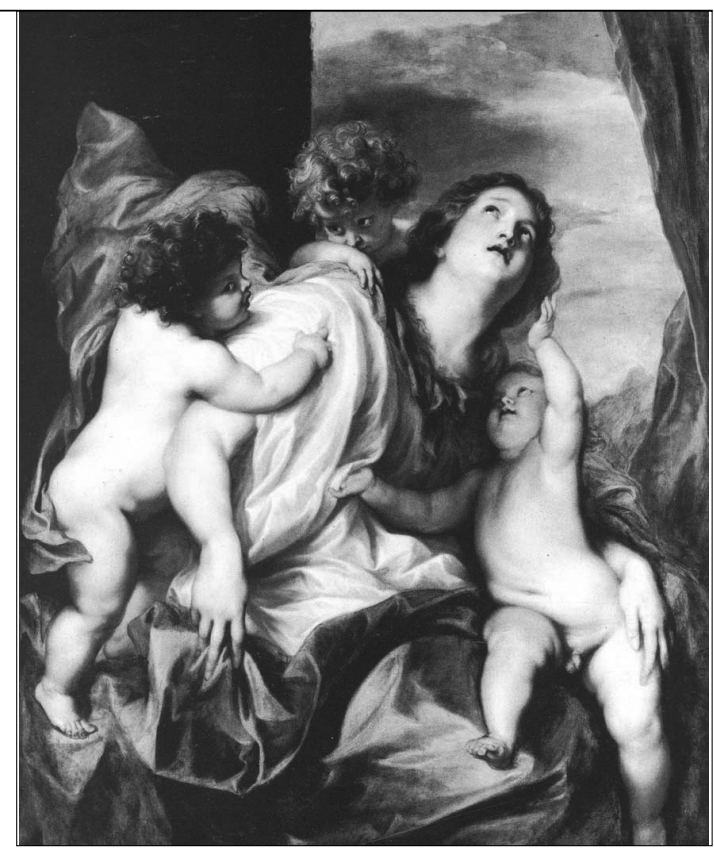

Fig. 4. Van Dyck, La Caridad, National Gallery, Londres

Jesús. Esta fecha corresponde al segundo periodo de Amberes (1627-1632), cuando pintaría este lienzo, muy afín al estilo de estos años, con éxito en el gusto de la clientela hispanófila residente en Amberes.

Las rosas que penden de los arbustos las recoge un ángel mancebo en un cesto a la izquierda. Otro, en el lado opuesto, lleva racimos de uvas. Son símbolos constantes en la iconografía mariana: las rosas rojas aluden al martirio, y las blancas a la pureza. El Cantar de los Cantares ve a la Virgen como rosa sin espinas ${ }^{3}$. Las uvas anuncian la sangre de Cristo derramada, y las cerezas, también símbolo de la Pasión, nos transmiten su eucarística dulzura. El presagio del futuro sacrificio del Hijo de Dios lo refleja el semblante triste de la Virgen, que vuelve su rostro con delirio al Hijo. La Virgen ofrece el sacrificio al devoto espectador. Un precedente podría ser La Virgen con Niño y Santo de la Pinacoteca de Viena de Tiziano, y muy posiblemente ensayó la composición en un dibujo invertido (como fue frecuente en Van Dyck al pasar a la obra definitiva) que conserva la colección Devonshire ( $n^{\circ} 101716$ verso) (fig. 5) ${ }^{4}$. El mismo esquema utilizó en el dibujo de la Caridad conservado en el Gabinete de Estampas del Museo del Louvre (fig. 3$)^{5}$ y lienzo de la Caridad de la National Gallery de Londres (6494) ${ }^{6}$ (fig. 4), con el niño que abraza a la alegoría femenina con los brazos en alto. De hecho es un modelo muy utilizado ya por Van Dyck en la santa Rosalía intercediendo por la peste de Palermo del Metropolitan Museum de

\footnotetext{
${ }^{3}$ G. Ferguson, Signs and Symbols in Christian Art, New York, 1956, p. 47; L. RÉAU, Iconographie de l'art chrétien, I-VI, París, 1957, II, p. 100.

${ }^{4}$ M. JafFé, The Devonshire Collection of Northern European Drawings, V.I, Turín, Londres, Venecia, 2002, p. 83, $\mathrm{n}^{\circ} 101716$ verso. Quizá siguiendo como sugiere Jaffé un original perdido de Veronés.

${ }^{5}$ P. 167x 150 mm. Gabinete de Dibujos del Museo del Louvre, París, Inv. nº 19912, (H. VeY, Die Zeichnungen Anton Van Dycks, Bruselas, 1962, p.200, $\mathrm{n}^{\circ} 133$ ).

6 The National Gallery Report 1982-1984, Londres, 1985, pp. 34-35.
} 
Fig. 5. Van Dyck, La Virgen con el Niño, dibujo, colección Devonshire, Chatsworth, Derbyshire, Inglaterra.
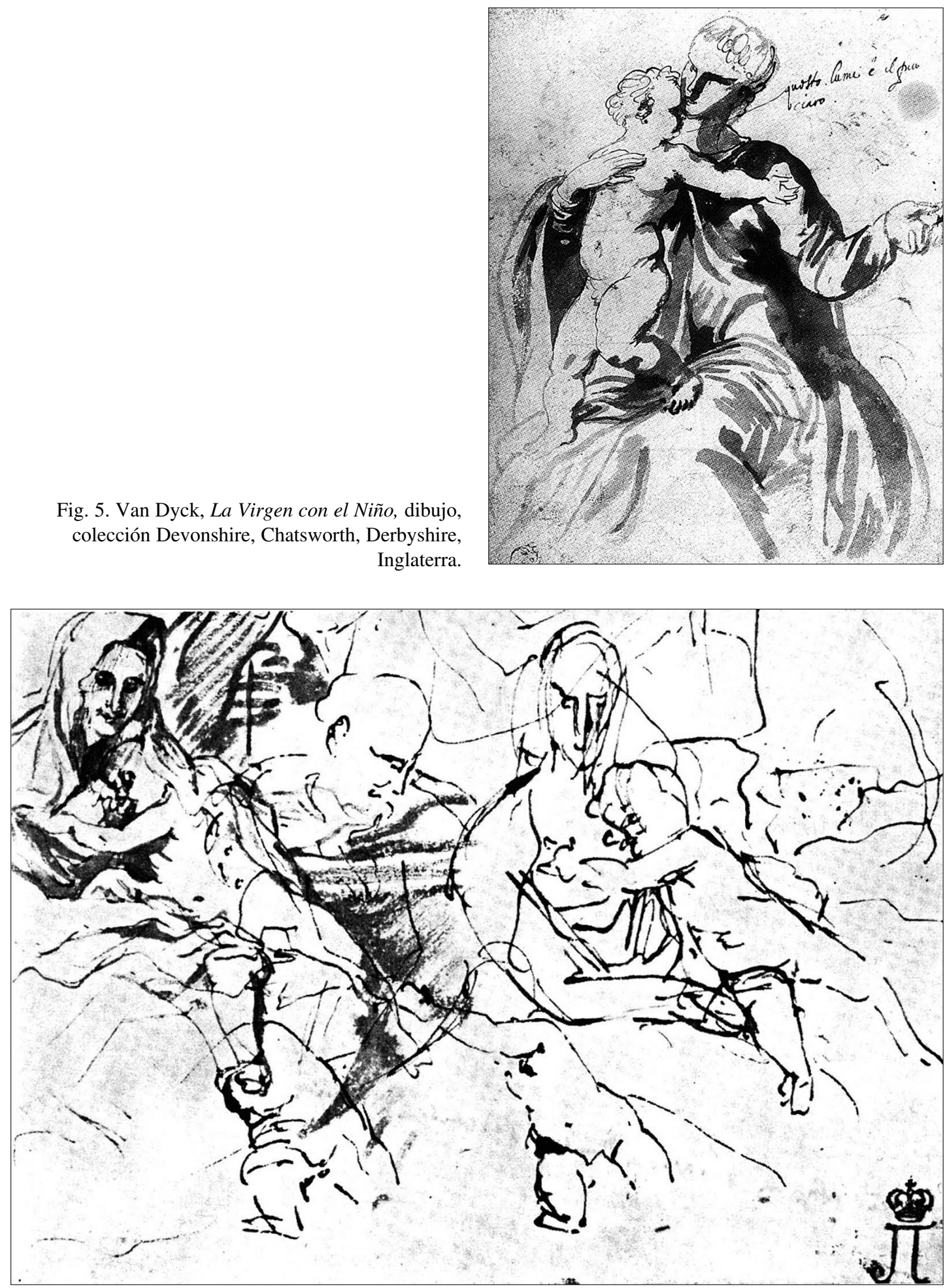

Fig. 6. Van Dyck, La Virgen con el Niño, dibujo, Gabinete de Dibujos del Ermitage, Leningrado. (detalle). 
Nueva York, en brusca diagonal ascendente. Ensayos, ajenos al asunto, del rostro de la Virgen, aunque abrazando el Niño a la madre están en el dibujo de María con el Niño del Ermitage [fig.6] ${ }^{7}$. El niño del lado opuesto en la Caridad es una transmutación en el mancebo del lienzo de la colección Osuna que estudiamos.

No vemos huellas tan ricas de carga emocional en los precursores y maestro de Van Dyck; ni Rubens, cuyo paralelo más próximo es la Virgen con Niño del Museo del Ermitage (1615) alcanza la emotividad impactante que Van Dyck derrochó en el semblante y mano con las cerezas en tan osado escorzo del lienzo de Osuna.

Este está registrado en la testamentaría de la casa Pastrana en 1868 con el no 34 "Un cuadro de Nuestra Señora, de medio cuerpo, con el Niño en los brazos, y en la mano tiene la Virgen dos guindas, y a los lados dos angeles con frutas, original de Antonio Wandit, tiene vara y tres dedos en cuadro, con marco dorado y labrado, tasado en 9000 reales de vellón"8; pasó luego a la casa ducal de Osuna, donde lo encontramos de nuevo inventariado en 1896, entre los Cuadros y demás objetos en el Palacio llamado de las Vistillas, en la posesión de La Alameda y en otros lugares, con la misma numeración: "34. Van Dyck (Antonio). Asunto místico. La Virgen con el Niño Dios en los brazos, es asistida y obsequiada por dos ángeles que la presentan canastillos de frutas: Lienzo, alto, 1,13. Ancho, 1,13"9. Desconocemos desde entonces su actual paradero.

MATÍAs Díaz PADRÓN Museo Nacional del Prado

\footnotetext{
${ }^{7}$ P. 122x171 mm. Gabinete de Dibujos, Ermitage, San Petersburgo, Inv. n 5870 . (H. Vey, op.cit. p. 201, $\mathrm{n}^{\circ}$ 134).

8 N. Sentenach, La Pintura en Madrid, 1907, p. 84; N. Sentenach, Joyas artísticas, 1896, nº 34.

${ }^{9}$ N. SEnTEnACh, Catálogo de los cuadros, esculturas, grabados y otros objetos artísticos de la antigua casa ducal de Osuna, expuestos en el Palacio de la Industria y de las Artes, segunda edición corregida y aumentada, Madrid, 1896, p. $16, \mathrm{n}^{\mathrm{o}} 34$.
} 